\title{
Health literacy and patient participation in multidisciplinary tumor conferences in breast cancer care: a multilevel modeling approach
}

Christian Heuser ${ }^{1,2^{*}} \mathbb{D}$, Annika Diekmann ${ }^{1,2}$, Christoph Kowalski ${ }^{3}$, Anna Enders ${ }^{4}$, Rupert Conrad ${ }^{5}$, Holger Pfaff $^{6}$, Lena Ansmann ${ }^{7}$ and Nicole Ernstmann ${ }^{1,2}$

\begin{abstract}
Background: Decisions made in multidisciplinary tumor conferences (MTC) that consider patient preferences result in better patient outcomes. Furthermore, it has been shown that in some breast cancer centers in Germany, patients participate in MTCs and that participation is associated with sociodemographic and breast cancer centerrelated factors. Health literacy $(\mathrm{HL})$ has been shown to be predictive for individual health behavior and is an important prerequisite for patient participation in healthcare. However, so far nothing is known about the association between HL and MTC patient participation. To close this gap in research, we analyzed which patient characteristics affect participation in MTCs and whether participation varies between breast cancer centers.

Methods: In a prospective, multicenter cohort study, newly diagnosed breast cancer patients were surveyed directly after surgery (T1) as well as 10 weeks (T2) and 40 weeks (T3) after surgery. After descriptive analysis, t-tests were conducted, correlations for independent variables were run, and logistic multilevel regression analysis was applied to estimate the association between patient participation in MTCs at T1 and HL (HLS-EU-Q16 [1]), sociodemographic and disease-related characteristics ( $n=863$ patients) and the variation between breast cancer centers ( $n=43$ centers).

Results: Descriptive results show that $6.8 \%$ of breast cancer patients took part in a MTC. The logistic multilevel regression model revealed that patients with an inadequately $\mathrm{HL}$ are less likely to participate in MTCs (OR $=0.31$, $95 \%-\mathrm{Cl}=0.1-0.9$, Pseudo- $\left.\mathrm{R}^{2}=0.06\right)$, and participation is dependent on the breast cancer center $($ ICC $=0.161)$.

Conclusions: These findings are the first to show significant differences in HL and patient participation in MTCs in a large sample of breast cancer patients. In future research on patient participation in MTCs and HL, questions concerning the organization, communication and decision-making in MTCs with and without patient participation have to be addressed, and patient and provider perspectives must be equally considered.
\end{abstract}

Trial registration: Database Health Services Research, VfD_PIAT_12_001630, registered prospectively on 01.03.2012.

Keywords: Health literacy, Multidisciplinary tumor conference, Tumor board, Patient participation, Breast Cancer, Health services research, Multilevel regression analysis

\footnotetext{
* Correspondence: christian.heuser@ukbonn.de

${ }^{1}$ Center for Health Communication and Health Services Research (CHSR),

Department of Psychosomatic Medicine and Psychotherapy, University

Hospital Bonn, Sigmund-Freud-Str. 25, 53127 Bonn, Germany

${ }^{2}$ Center for Integrated Oncology (ClO Bonn), University Hospital Bonn,

Sigmund-Freud-Str. 25, 53127 Bonn, Germany

Full list of author information is available at the end of the article
}

(c) The Author(s). 2019 Open Access This article is distributed under the terms of the Creative Commons Attribution 4.0 International License (http://creativecommons.org/licenses/by/4.0/), which permits unrestricted use, distribution, and reproduction in any medium, provided you give appropriate credit to the original author(s) and the source, provide a link to the Creative Commons license, and indicate if changes were made. The Creative Commons Public Domain Dedication waiver (http://creativecommons.org/publicdomain/zero/1.0/) applies to the data made available in this article, unless otherwise stated. 


\section{Background}

Oncological healthcare has been faced with many developments in recent years. Among them are multidisciplinary care as a process aiming to foster cooperation between professionals from a range of disciplines [2] as well as patient centered care as a healthcare process aiming to achieve socially and psychologically integrated care [3]. Multidisciplinary tumor conferences (MTCs) mainly represent the first development as a regular exchange between healthcare professionals [4, 5]. It remains unclear if MTCs could as well incorporate processes and structures of patient centeredness to foster decisions that explicitly consider patient preferences [6, 7]. International studies have revealed that decisions in MTCs that consider patient preferences result in better patient outcomes [8-10]. However, it has been shown that patient preferences concerning decision-making are not considered systematically in MTCs and treatment recommendations are mainly based on clinical information [11-13]. Many decisions in breast cancer care are preference-sensitive, especially in metastatic breast cancer treatment [14]. Therefore, incorporating patient preferences in MTCs is a central factor in treatment decision-making to achieve higher-quality decisions [15] and to possibly optimize adherence efficiency of MTC decisions [16].

In an effort to better take patient preferences into account, the participation of patients in MTCs has been widely discussed recently. In Germany, MTCs are part of the certification criteria of the German Cancer Society and the Medical Council of North Rhine-Westphalia [17]. The requirements of the Medical Council of North Rhine-Westphalia demand that patients should be allowed to participate in MTCs for the discussion of their own case [18]. Initial findings indicate that the active participation of patients in MTCs, e.g. concerning decision-making, is important $[19,20]$ because it may increase patient compliance and satisfaction [21-23]. Participating patients define themselves as collaborating actors who are able to state their preferences in the process of decision-making [24]. From the healthcare providers' perspective, discussing therapy options with patients in the context of MTCs might be seen as a challenging part of their profession [25]. Besides potential benefits of patient participation in MTCs, studies indicate possible negative consequences for patients and providers. Patients may not fully understand the complexity of clinical information, which may increase fear regarding therapy and prognosis [26]. Moreover, the discussion between providers might be restricted. Medical experts may find it difficult to discuss a complex medical case in the presence of patients due to the need to adjust their language and to think about possible misinterpretations of their medical evaluations by the patient [27]. Further challenges might include organizational barriers, e.g. time pressure and difficult management of the patient invitation [28].
All in all, first hints concerning risks and benefits of MTC patient participation exist. To better understand how to make patient participation in MTCs beneficial, we need to know which patient subgroups are participating in MTCs in the first place, especially because we know that in some breast cancer centers in Germany, patients participate in MTCs [29]. As patients do not regularly participate in MTCs, however, little is known about the associated benefits and risks as well as participating patient subgroups. Therefore, it is important to understand which patient subgroups are likely to participate in MTCs to get a better knowledge on which patients might be more likely to find MTCs beneficial or detrimental.

In this context, one prior research shows that patients' invitation to and participation in MTCs depends on individual sociodemographic and disease-related characteristics [30]. However, little is known about further patient characteristics. As health literacy (HL) has been shown to be predictive for individual health behavior and to be an important prerequisite for patient participation in healthcare [31, 32], it can be assumed that patients with sufficient HL are more likely to participate in MTCs. According to Sorensen et al., HL is defined as the knowledge, motivation and competence to access, understand, appraise and apply health information [33]. $\mathrm{HL}$ is an important factor in responding to the complex demands of modern healthcare systems, e.g., concerning the use of healthcare services, patient-provider communication, better health outcomes or disease prevention [32-36]. Previous studies found an increased prevalence of low HL especially among people with low education, older age, chronic disease or an ethnic background [1, 37]. In addition, HL does not depend on individual characteristics alone, but at the same time is a product of individuals' capacities in an organizational setting and demands of the healthcare system, which make up organizational HL [38-40]. So far, nothing is known about the association between individual HL and patient participation in MTCs.

\section{Research aim}

This is the first study analyzing the possible association between HL and patient participation in MTCs. The aim is to analyze the impact of individual HL, sociodemographic and disease-related characteristics as well as the impact of the variation between breast cancer centers on patient participation in MTCs.

\section{Methods}

\section{Study design and sample}

In a prospective, multicenter cohort study, ${ }^{1}$ newly diagnosed breast cancer patients were surveyed directly after (T1), 10 weeks after (T2) and 40 weeks after (T3) surgery, with three reminders sent according to Dillman's Total Design Method [41]. Patients needed to give written informed consent to take part in the survey. The survey was approved by the 
Ethics Committee of the Medical Faculty of the University of Cologne. Data were collected from 2013 to 2014 using standardized self-report measures in written questionnaires. Breast cancer centers were recruited by randomly sampling 98 out of 247 German breast cancer centers meeting the criteria of the German Cancer Society and the German Society for Senology. In total $n=56$ breast cancer centers took part in the study and $n=43$ were included in the analysis of the study; this discrepancy is due to missing or insufficient patient data in some centers. Patient inclusion criteria were inpatient surgery for newly diagnosed breast cancer (C50.xx, D05.xx) performed between February 01 and August 31, 2013, at least one malignancy and at least one postoperative histological evaluation. In total, 1395 patients took part in the study (response rate $=87.7 \%$ ), with $n=863(61.9 \%)$ patients included in the analysis, with the discrepancy due to missing data in dependent and independent variables.

\section{Instruments and variables}

All measures and instruments used in the questionnaires were pre-tested in a pilot study as described elsewhere [42, 43]. All items used in this manuscript were measured in T1. Patients who filled out the item "Have you been offered the opportunity to participate in a tumor conference?", (1 $=$ Yes and I took it; $2=$ Yes and I did not take it; $3=$ No) were considered. The item was used as dependent variable in order to measure the participation in MTC $(0=$ "No" and "Yes and I did not take it"; 1 = "Yes and I took it"). HL was measured with the validated HLS-EU-Q16 questionnaire. HLS-EU-Q16 was categorized into 'sufficient', 'problematic' and 'inadequate' categories according to common standards [1] (Cronbach's Alpha 0.90). Data on sociodemographic patient characteristics were assessed in the patient survey with the help of self-reported items (formal education, age, health literacy, living with partner, native language, health insurance status). Data on clinical patient characteristics were provided by the clinical personnel (UICC stage). Table 1 shows the descriptive results of the 863 patients and 43 breast cancer centers included in the model.

\section{Analysis}

Firstly, the data were analyzed descriptively. Secondly, intercorrelations among the independent variables were checked for multicollinearity. Lastly, the associations between patient participation in MTCs and HL, sociodemographic and disease-related characteristics were analyzed using two-level random intercept hierarchical logistic models. As the data were hierarchically structured, i.e., individual patient data were nested in breast cancer center clusters, multilevel modeling was used to account for clustering [44, 45]. In a first step, a two-level model without predictors (null model) was fitted in order to calculate the intraclass correlation coefficient (ICC null model). The ICC indicates the proportion of variance in the dependent variable that is attributable to differences between breast cancer centers. In a second step, patient characteristics were added as predictors at the patient level. The resulting odds ratios (OR) and $95 \%$ confidence intervals $(95 \%-\mathrm{CI})$ were standardized via standard deviations to allow comparisons of effect sizes. No imputations were performed for missing data. Due to listwise deletion for the dependent variable and all independent variables, individual data of $n=863$ patients and organizational data of $n=43$ centers were included in the model. All analyses were conducted with STATA version 15.

\section{Results}

\section{Descriptive analyses}

According to the survey, 59 patients $(6.8 \%)$ took part in MTCs. For detailed descriptive results of the sample see Table 1.

Table 1 Descriptive results of the $n=863$ patients

\begin{tabular}{|c|c|c|}
\hline Variables & Response trait & $n(\%)$ \\
\hline \multirow{2}{*}{$\begin{array}{l}\text { Dependent variable: } \\
\text { participation in MTC }\end{array}$} & No & $804(93.2)$ \\
\hline & Yes & $59(6.8)$ \\
\hline \multirow{4}{*}{$\begin{array}{l}\text { Highest education } \\
\text { level achieved }\end{array}$} & No school education & $62(7.2)$ \\
\hline & Lower secondary school education & $503(58.3)$ \\
\hline & $\begin{array}{l}\text { Intermediate secondary school } \\
\text { education }\end{array}$ & $101(11.7)$ \\
\hline & $\begin{array}{l}\text { Entrance certificate for a university } \\
\text { of applied sciences / University } \\
\text { entrance certificate }\end{array}$ & $197(22.8)$ \\
\hline \multirow[t]{5}{*}{ Age } & $18-39$ & $36(4.2)$ \\
\hline & $40-49$ & $193(22.4)$ \\
\hline & $50-59$ & $273(31.6)$ \\
\hline & $60-69$ & 204 (23.6) \\
\hline & $\geq 70$ & $157(18.2)$ \\
\hline \multirow[t]{3}{*}{ Health literacy } & Inadequate & $139(16.1)$ \\
\hline & Problematic & $287(33.3)$ \\
\hline & Sufficient & $437(50.6)$ \\
\hline \multirow[t]{2}{*}{ Living with partner } & No & $222(25.7)$ \\
\hline & Yes & $641(73.2)$ \\
\hline \multirow[t]{2}{*}{ Native language } & German & $827(95.8)$ \\
\hline & Other & $36(4.2)$ \\
\hline \multirow{3}{*}{$\begin{array}{l}\text { Health insurance } \\
\text { status }\end{array}$} & Statutory & $659(76.4)$ \\
\hline & Private & $89(10.3)$ \\
\hline & $\begin{array}{l}\text { Statutory with additional private } \\
\text { insurance }\end{array}$ & $115(13.3)$ \\
\hline \multirow[t]{3}{*}{ UICC stage } & Stage 0 / I & $441(51.1)$ \\
\hline & Stage II & $300(34.8)$ \\
\hline & Stage III / IV & $122(14.1)$ \\
\hline$n$ patients & & 863 \\
\hline $\begin{array}{l}n \text { breast cancer } \\
\text { centers }\end{array}$ & & 43 \\
\hline
\end{tabular}


Table 2 T-test results with HL status and MTC patient participation

\begin{tabular}{lll}
\hline $\mathrm{HL}$ & Participating patients & Non-participating patients \\
\hline Inadequate & $6.8 \%$ & $16.8 \%$ \\
Problematic & $32.3 \%$ & $33.3 \%$ \\
Sufficient & $61.0 \%$ & $49.9 \%$ \\
& Mean: 2.54 & Mean: 2.33 \\
& SD: 0.62 & SD: 0.75 \\
& $95 \%-C l: 2.38-2.70$ & $95 \%-$ Cl: $2.28-2.38$ \\
\hline
\end{tabular}

Sufficient HL scores were found in $61 \%$ of the participating patients, whereas $32.3 \%$ exhibited problematic and $6.8 \%$ inadequate HL. Of the non-participating patients, $49.9 \%$ had sufficient HL, 33.3\% problematic HL and $16.8 \%$ inadequate HL. T-tests revealed that the HL status of participating patients (mean 2.54) and non-participating patients (mean 2.33) significantly differed $(t=-2.12$, $p=.05)$. T-test results are shown in Table 2 . The proportion of patients participating in MTCs in the 43 breast cancer centers ranged from 0 to $75 \%$.

\section{Multivariate analyses}

No multicollinearity was found between the independent variables. The logistic multilevel regression model revealed that HL is significantly associated with the participation of breast cancer patients in MTCs (Pseudo- $\mathrm{R}^{2}=0.06$ ). Patients with inadequately $\mathrm{HL}$ are less likely to participate in MTCs $(\mathrm{OR}=0.31,95 \%-\mathrm{CI}=$ 0.1-0.9) than patients with sufficient HL. Concerning other sociodemographic or disease-related characteristics, no significant associations were found in the model. The ICC shows a value of $0.161(16.1 \%)$ and the ICC null model of 0.149 (14.9\%) indicating that $14.9 \%$ of the variance in the dependent variable (patient participation on MTC) is associated to differences only between breast cancer centers (level 2). All results are shown in Table 3.

Table 3 Logistic multilevel hierarchical regression model with participation in the MTC as the dependent variable

\begin{tabular}{|c|c|c|c|}
\hline Variables & Response trait & $\mathrm{OR}^{1}$ & $95 \%-\mathrm{Cl}^{2}$ \\
\hline \multirow[t]{4}{*}{ Highest education level achieved } & No school education & 1.93 & $0.74-5.31$ \\
\hline & Lower secondary school education (Ref.) & 1.00 & \\
\hline & Intermediate secondary school education & 1.74 & $0.75-3.97$ \\
\hline & Entrance certificate for a university of applied sciences / University entrance certificate & 1.12 & $0.54-2.34$ \\
\hline \multirow[t]{5}{*}{ Age } & $18-39$ & 0.39 & $0.10-3.15$ \\
\hline & $40-49$ & 0.69 & $0.30-1.56$ \\
\hline & 50-59 (Ref.) & 1.00 & \\
\hline & $60-69$ & 0.80 & $0.38-1.69$ \\
\hline & $\geq 70$ & 0.93 & $0.42-2.08$ \\
\hline \multirow[t]{3}{*}{ Health literacy } & Inadequate & 0.31 & $0.11-0.93$ \\
\hline & Problematic & 0.85 & $0.47-1.56$ \\
\hline & Sufficient (Ref.) & 1.00 & \\
\hline \multirow[t]{2}{*}{ Living with partner } & No & 1.00 & \\
\hline & Yes & 0.92 & $0.48-1.75$ \\
\hline \multirow[t]{2}{*}{ Native language } & German & 1.00 & \\
\hline & Other & 1.89 & $0.49-7.23$ \\
\hline \multirow[t]{3}{*}{ Health insurance status } & Statutory (Ref.) & 1.00 & \\
\hline & Private & 0.74 & $0.26-2.12$ \\
\hline & Statutory with additional private insurance & 0.95 & $0.39-2.27$ \\
\hline \multirow[t]{3}{*}{ UICC stage } & Stage 0 / I (Ref.) & 1.00 & \\
\hline & Stage II & 0.83 & $0.45-1.53$ \\
\hline & Stage III / IV & 0.39 & $0.13-1.18$ \\
\hline$n$ patients & & 863 & \\
\hline$n$ breast cancer centers & & 43 & \\
\hline ICC $^{3}$ (ICC null model) & & $0.161(0.149)$ & \\
\hline
\end{tabular}

${ }^{1}$ Standardized odds ratios (OR)

${ }^{2} 95 \%$-confidence intervals $(95 \%$-Cl)

${ }^{3}$ Intraclass correlation coefficient (ICC)

Significant results in bold $(p<0.05)$ 


\section{Discussion}

The aim of the study was to examine how HL, sociodemographic patient characteristics and disease-related patient characteristics are associated with patient participation in MTCs and to what extent patient participation in MTCs varies between breast cancer centers. The logistic multilevel regression model showed that significant differences in participation exist between HL level groups and between breast cancer centers. To the best of our knowledge, our findings show this association for the first time. In the following sections, specific aspects of these results are discussed in detail.

\section{Patient characteristics}

Descriptive results show that $6.8 \%$ of breast cancer patients in German breast cancer centers took part in MTCs, which is a slightly lower percentage than in other studies based on data from North Rhine-Westphalia [30]. This may be due to the two different requirement catalogues of breast cancer centers in Germany: The Medical Council of North Rhine-Westphalia demands that patients should be allowed to participate in MTCs for the discussion of their own case, which led to a call for invitation to MTCs. In contrast, the German Cancer Society (Germany-wide) does not demand patient participation in MTCs.

The descriptive and multivariate results of our analyses reveal that patients with an inadequately $\mathrm{HL}$ are less likely to participate in MTCs. Our results are in line with research on the implications of individual $\mathrm{HL}$ on health-related behavior [32, 34]. Higher HL enables patients to better communicate with healthcare professionals and to be more involved in diagnosis and treatment $[36,46]$. This may ultimately lead to better health process measures and health outcomes $[1,33,35]$.

As patients' formal education, age, native language, partner status and health insurance showed no significant association in the model, it can be concluded that in the here presented sample of breast cancer survivors sociodemographic characteristics are not associated with patient participation in MTCs. This might be seen as contradictory to common findings as highly educated and/or younger patients would be more likely to participate in MTC due to greater HL, greater coping skills and stronger preferred involvement in decision-making [47, 48]. Prior findings from Ansmann et al. on patient participation in MTCs show opposite findings as well [30]. One explanation might be the lack of a definition of "MTC" given in the questionnaire potentially leading to a misunderstanding of the questionnaire item "participation in MTC". This might indicate that patients with lower education possibly have a greater tendency to respond socially desirable (MTC participation "yes"). Another reason might be an inconsistent invitation of patients from healthcare providers as patients might be selected based on sociodemographic and/or disease-related characteristics. Lastly, missing data has to be taken into account: patients with lower education, higher age, inadequately health literacy, native language not "German" and statutory health insurance status descriptively show a greater amount of missing data.

The model shows no significant associations for the UICC stage. This result stands in contrast to prior findings [30] and to the hypothesis that patients with a UICC stage III/IV take part more frequently in MTCs because in advanced disease stages, more treatment options can be discussed and therefore patients may think that they can benefit more from stating their preferences in the decision-making process. The absence of differences in our study might be explained, on the one hand, by the small number of patients in the categories UICC stage III/IV. On the other hand, from the perspective of severely compromised patients with UICC stage III/IV, the physical and emotional effort associated with participating in MTCs may outweigh potential benefits of their involvement in the decision-making process.

\section{Breast cancer center variation}

Prior findings showed that invitations extended to patients to take part in a MTC and actual participation rates vary significantly between breast cancer centers [30]. The ICC for the null model implies that $14.9 \%$ of the variance in participation in MTCs is attributable to the breast cancer center. The rather high ICC underlines the fact that providers' attitudes towards patient participation in MTCs as well as the associated processes before, during and after MTCs differ quite strongly between breast cancer centers. This leads to research implications regarding the examination of specific risks and benefits emerging from patient participation in MTCs for patients and providers across various centers. After this examination the question can be raised whether MTC participation and the processes to ensure participation might be one aspect of organizational HL [49] in the sense of patient centeredness.

\section{Limitations and strengths}

When interpreting these findings, some limitations, strengths as well as future research and practice implications have to be considered. As a limitation, the observational design with mainly self-reported items has to be taken into account; it might contain a possible systematic error in the variance of the dependent variable. Furthermore, three patient selection processes might have taken place: firstly, only women were included in the analysis, secondly, although we are not able to test it, we suggest that healthier patients might have filled out the questionnaire more often and lastly, the characteristics of patients with missing data (see "Patient characteristics"). Another 
source of overestimation of associations might be the common method bias. Overall, no causal effects can be formulated due to the observational design. A strength of the study is the nationwide random sample of breast cancer centers and patients. Furthermore, we considered the nested data structure with the multilevel modelling approach. Additionally, the multilevel regression model can be seen as an advanced statistical method combining many patient variables in one model.

\section{Implications}

As research implications for this study, four main aspects have to be taken into account. (1) In general, our results supply no evidence regarding the risks and benefits of patient participation in MTCs for patients and providers. Concerning future study designs, a triangulation [50] of different qualitative and quantitative methods is needed to better equally address the perspectives of patients and providers on MTC participation. Such a mixed-methods study [51] on risks and benefits might include patient experiences of MTC participation and their psychosocial situation as well as provider perspectives of possible opportunities associated with and barriers to patient participation in MTCs. In addition, a future study might be able to clarify the association between the sociodemographic characteristics included here and the likelihood of participation. Ideally, future research would benefit from an interventional study design. (2) Research on patient participation in MTCs and HL differences has to give greater consideration to healthcare processes. Patient-provider communication and decision-making in MTCs have to be additionally addressed with the help of different concepts [46]. This might include, e.g. the patients' perspective on organizational patient-centred efforts in MTCs in order to analyze healthcare organizations' responsiveness to patients' individual needs in decision-making and patient-provider communication during MTC. This seems to be an important aspect of HL for future research as communicational processes and skills are considered increasingly important in healthcare. A research-guiding hypothesis in this context is the abovementioned question of whether MTCs in their common form represent processes and structures of patient centeredness, because they mainly consist of decisions which consider patient preferences $[6,52]$. This might include the question of whether the participation of patients in MTCs is an effective tool to realize patient centeredness. Therefore, relevant aspects (see (1)) have to be compared in MTCs with and without patient participation. (3) The interesting interaction between HL and sociodemographic characteristics, which is increasingly discussed in Germany [37, 53], should be considered more strongly in MTC research. (4) As the missing data contains patient subgroups which represent potential vulnerable groups in healthcare (low education, higher age, low health literacy) it is important for future studies to follow strategies reaching these patients. This might include the adjustment of survey instruments in simple language, the use of qualitative research approaches instead of using standardized quantitative instruments which are potentially difficult to fill out, and the cooperation with organized patient groups (e.g. self-help groups) in order to integrate research questions focusing on specific (information) needs or (emotional) concerns, e.g. the procedures of a MTC.

As practical implications for level 2 (organization and providers), it is worth considering factors that may possibly encourage or hinder the adoption of patient participation in MTCs. This may include the following aspects concerning the organization of MTCs: the selection and the consistent or inconsistent invitation of patients, a verbally and written definition of and invitation to the MTC which is easily understandable for all patients, the duration of the MTC per patient, the number of discussed cases in one MTC, interruptions during MTCs, or documents and technical aids. Furthermore, processes in the MTCs like the interaction between the providers as well as the interaction between providers and patients must be studied. Lastly, to include provider and breast cancer center manager attitudes towards patient-centered approaches, the provider experiences concerning the involvement of patients in the decision-making process is important. For level 1 (patients), the subjective experiences of patients in MTCs are important in order to explore the potential risks and benefits of participation. This may include patient expectations, concerns, and fears before and after the MTC and patient experiences concerning the decision-making.

\section{Conclusions}

This study has highlighted a significant research gap concerning the individual and organizational determinants of patient participation in MTCs among breast cancer patients. The findings show that significant differences in MTC patient participation exist between patient groups (individual HL) and between breast cancer centers, and hence demonstrate the necessity of more research in this field. Overall, future research and practice should answer the questions regarding risks and benefits of patient participation in MTCs. Deeper insight into the feasibility of patient participation in MTCs, possible subgroups of patients that might benefit from participation as well as the quality of the decision-making process would be beneficial in the development of specific recommendations for patients and providers in MTCs. 


\section{Endnotes}

${ }^{1}$ PIAT: Strengthening patient competence: Breast cancer patients' information and training needs (Funding: The German Federal Ministry of Health; Carried out by: Institute for Medical Sociology, Health Services Research, and Rehabilitation Science (IMVR))

\section{Acknowledgements}

We would like to thank all of the patients and breast cancer centers participating in the study.

\section{Funding}

This study was funded by The German Federal Ministry of Health.

\section{Availability of data and materials}

Data and all other materials for this study are kept at the Institute of Medical Sociology, Health Services Research and Rehabilitation Science, University of Cologne, Germany. The datasets generated and analysed during the current study are not publicly available due to terms of written informed consent to which the participants agreed but are available from the corresponding author on reasonable request.

\section{Authors' contributions}

$\mathrm{CH}$ planned and conducted data analyses, drafted and revised all sections of the paper and is guarantor. AD, RC and LA assisted in data analysis, interpretation of the results and editing the manuscript. HP, CK, AE and NE developed the study framework and patient survey and assisted in data analyses, interpretation of the results and editing the manuscript. All authors read and approved the final manuscript.

\section{Ethics approval and consent to participate}

All procedures performed in studies involving human participants were in accordance with the ethical standards of the institutional and/or national research committee and with the 1964 Helsinki declaration and its later amendments or comparable ethical standards. This study was approved by the ethics committee of the Medical Faculty of the University of Cologne, Germany. Written informed consent was obtained from all individual participants included in the study.

\section{Consent for publication}

Not applicable.

\section{Competing interests}

The authors declare that they have no competing interests.

\section{Publisher's Note}

Springer Nature remains neutral with regard to jurisdictional claims in published maps and institutional affiliations.

\footnotetext{
Author details

${ }^{1}$ Center for Health Communication and Health Services Research (CHSR), Department of Psychosomatic Medicine and Psychotherapy, University Hospital Bonn, Sigmund-Freud-Str. 25, 53127 Bonn, Germany. ${ }^{2}$ Center for Integrated Oncology (ClO Bonn), University Hospital Bonn, Sigmund-Freud-Str. 25, 53127 Bonn, Germany. ${ }^{3}$ German Cancer Society e.V. (DKG), Department for Certification, Kuno-Fischer-Straße 8, 14057 Berlin, Germany. ${ }^{4}$ Department for Research and Quality Management, The Federal Centre for Health Education (BZgA), Maarweg 149-161, 50825 Cologne, Germany. ${ }^{5}$ Department of Psychosomatic Medicine and Psychotherapy, University Hospital Bonn, Sigmund-Freud-Str. 25, 53127 Bonn, Germany. ${ }^{6}$ Institute of Medical Sociology, Health Services Research, and Rehabilitation Science (IMVR), Faculty of Human Sciences and Faculty of Medicine, University of Cologne, Eupener Str. 129, 50933 Cologne, Germany. ${ }^{7}$ Organizational Health Services Research, Department for Health Services Research, Carl von Ossietzky University of Oldenburg, Ammerlaender Heerstraße 140, 26129 Oldenburg, Germany.
}

Received: 9 October 2018 Accepted: 28 March 2019

Published online: 08 April 2019

\section{References}

1. HLS-EU Consortium. Comparative report of health literacy in eight EU member states. The European Health Literacy Survey HLS-EU. 2012.

2. Prades J, Remue E, van Hoof E, Borras JM. Is it worth reorganising cancer services on the basis of multidisciplinary teams (MDTs)? A systematic review of the objectives and organisation of MDTs and their impact on patient outcomes. Health Policy. 2015;119:464-74. https://doi.org/10.1016/j. healthpol.2014.09.006.

3. Stewart M. Patient-centered medicine: transforming the clinical method. 4th ed. Thousand Oaks: SAGE Publ; 1997.

4. Taylor C, Atkins L, Richardson A, Tarrant R, Ramirez A-J. Measuring the quality of MDT working: an observational approach. BMC Cancer. 2012;12: 202. https://doi.org/10.1186/1471-2407-12-202.

5. Croke JM, El-Sayed S. Multidisciplinary management of cancer patients: chasing a shadow or real value? An overview of the literature. Curr Oncol. 2012;19:232-8. https://doi.org/10.3747/co.19.944.

6. Scholl I, Zill JM, Härter M, Dirmaier J. An integrative model of patientcenteredness - a systematic review and concept analysis. PLoS One. 2014;9: e107828. https://doi.org/10.1371/journal.pone.0107828.

7. Hahlweg P, Didi S, Kriston L, Härter M, Nestoriuc Y, Scholl I. Process quality of decision-making in multidisciplinary cancer team meetings: a structured observational study. BMC Cancer. 2017;17:772. https://doi.org/10.1186/ s12885-017-3768-5.

8. Raine R, Wallace I, Nic a' Bhaird C, Xanthopoulou P, Lanceley A, Clarke A, et al. Improving the effectiveness of multidisciplinary team meetings for patients with chronic diseases:: a prospective observational study. Health Servives and Delivery Research 2014. doi:https://doi.org/10.3310/hsdr02370.

9. Taylor C, Finnegan-John J, Green JSA. "No decision about me without me" in the context of cancer multidisciplinary team meetings: a qualitative interview study. BMC Health Serv Res. 2014;14:488. https://doi.org/10.1186/ s12913-014-0488-2.

10. Lamb BW, Taylor C, Lamb JN, Strickland SL, Vincent C, Green JSA, Sevdalis N Facilitators and barriers to teamworking and patient centeredness in multidisciplinary cancer teams: findings of a national study. Ann Surg Oncol. 2013;20:1408-16. https://doi.org/10.1245/s10434-012-2676-9.

11. Hahlweg P, Hoffmann J, Harter M, Frosch DL, Elwyn G, Scholl I. In absentia: an exploratory study of how patients are considered in multidisciplinary cancer team meetings. PLoS One. 2015;10:e0139921. https://doi.org/10. 1371/journal.pone.0139921.

12. Soukup T, Lamb BW, Sarkar S, Arora S, Shah S, Darzi A, et al. Predictors of treatment decisions in multidisciplinary oncology meetings: a quantitative observational study. Ann Surg Oncol. 2016;23:4410-7. https://doi.org/10. 1245/s10434-016-5347-4

13. Street RL, Elwyn G, Epstein RM. Patient preferences and healthcare outcomes: an ecological perspective. Expert Review of Pharmacoeconomics \& Outcomes Research. 2012;12:167-80. https://doi.org/10.1586/erp.12.3.

14. van de Haterd J, Voogdt-Pruis $H$, Raats I, van den Brink $R$, van Veenendaal $H$. Preference-sensitive decisions of patients with metastatic breast cancer: the need for decision support. Patient Experience J. 2016;3:50-6.

15. Stacey D, Samant R, Bennett C. Decision making in oncology: a review of patient decision aids to support patient participation. CA Cancer J Clin. 2008;58:293-304. https://doi.org/10.3322/CA.2008.0006.

16. Hollunder $\mathrm{S}$, Herrlinger U, Zipfel M, Schmolders J, Janzen V, Thiesler T, et al. Cross-sectional increase of adherence to multidisciplinary tumor board decisions. BMC Cancer. 2018;18:936. https://doi.org/10.1186/s12885-0184841-4.

17. Haier J. Tasks and limitations of tumor boards [Aufgaben und Grenzen von Tumorkonferenzen]. Onkologe. 2016;22:184-91. https://doi.org/10.1007/ s00761-015-2939-8.

18. Medical Association Westfalen-Lippe. Certification of breast cancer centers in North-Rhine Westphalia. Requirement catalogue breast cancer centers: [Verfahren zur Zertifizierung von Brustzentren in NRW. AnforderungskatalogBrustzentren]; 2018.

19. Choy ET, Chiu A, Butow P, Young J, Spillane A. A pilot study to evaluate the impact of involving breast cancer patients in the multidisciplinary discussion of their disease and treatment plan. Breast. 2007;16:178-89. https://doi.org/10.1016/j.breast.2006.10.002. 
20. Vahdat S, Hamzehgardeshi L, Hessam S, Hamzehgardeshi Z. Patient involvement in health care decision making: a review. Iran Red Crescent Med J. 2014;16:e12454. https://doi.org/10.5812/ircmj.12454.

21. Komatsu H, Nakayama K, Togari T, Suzuki K, Hayashi N, Murakami Y, et al. Information sharing and case conference among the multidisciplinary team improve patients' perceptions of care. Open Nurs J. 2011;5:79-85. https:// doi.org/10.2174/1874434601105010079.

22. Dew K, Stubbe M, Signal L, Stairmand J, Dennett E, Koea J, et al. Cancer care decision making in multidisciplinary meetings. Qual Health Res. 2015;25: 397-407. https://doi.org/10.1177/1049732314553010.

23. Taylor C, Munro AJ, Glynne-Jones R, Griffith C, Trevatt P, Richards M, Ramirez AJ. Multidisciplinary team working in cancer: what is the evidence? BMJ. 2010;340:c951. https://doi.org/10.1136/bmj.c951

24. Hubbard G, Kidd L, Donaghy E. Preferences for involvement in treatment decision making of patients with cancer: a review of the literature. Eur J Oncol Nurs. 2008;12:299-318. https://doi.org/10.1016/j.ejon.2008.03.004.

25. Salloch S, Ritter P, Wascher S, Vollmann J, Schildmann J. Medical expertise and patient involvement: a multiperspective qualitative observation study of the patient's role in oncological decision making. Oncologist. 2014;19:65460. https://doi.org/10.1634/theoncologist.2013-0268.

26. Devitt B, Philip J, McLachlan S-A. Team dynamics, decision making, and attitudes toward multidisciplinary cancer meetings: health professionals' perspectives. J Oncol Pract. 2010;6:e17-20. https://doi.org/10.1200/JOP.2010. 000023

27. O'Brien MA, Ellis PM, Whelan TJ, Charles C, Gafni A, Lovrics P, et al. Physician-related facilitators and barriers to patient involvement in treatment decision making in early stage breast cancer: perspectives of physicians and patients. Health Expect. 2013;16:373-84. https://doi.org/10. 1111/j.1369-7625.2011.00712.x.

28. Butow P, Harrison JD, Choy ET, Young JM, Spillane A, Evans A. Health professional and consumer views on involving breast cancer patients in the multidisciplinary discussion of their disease and treatment plan. Cancer. 2007;110:1937-44. https://doi.org/10.1002/cncr.23007.

29. Ansmann L, Ernstmann N. Patient participation in tumor conferences in breast cancer centers in North-Rhine Westphalia - the perspective of participating patients: [Patientinnenteilnahme an Tumorboards in NRW-Brustzentren - die Sicht teilnehmender Patientinnen]. Senologie - Zeitschrift für Mammadiagnostik und -therapie. 2015. https://doi.org/10.1055/s-0035-1550449.

30. Ansmann L, Kowalski C, Pfaff H, Wuerstlein R, Wirtz MA, Ernstmann N. Patient participation in multidisciplinary tumor conferences. Breast. 2014;23: 865-9. https://doi.org/10.1016/j.breast.2014.09.004.

31. Bauer $U$, Bittlingmayer UH, Richter $M$, editors. Health Inequalities: determinants and mechanisms [Determinanten und Mechanismen gesundheitlicher Ungleichheit]. 1st ed. Wiesbaden: VS Verlag für Sozialwissenschaften; 2008.

32. von Wagner C, Steptoe A, Wolf MS, Wardle J. Health literacy and health actions: a review and a framework from health psychology. Health Educ Behav. 2009;36:860-77. https://doi.org/10.1177/1090198108322819.

33. Sørensen K, van den Broucke S, Fullam J, Doyle G, Pelikan J, Slonska Z, Brand $\mathrm{H}$. Health literacy and public health: a systematic review and integration of definitions and models. BMC Public Health. 2012;12:80. https://doi.org/10.1186/1471-2458-12-80.

34. Nutbeam D. The evolving concept of health literacy. Soc Sci Med. 2008;67: 2072-8. https://doi.org/10.1016/j.socscimed.2008.09.050.

35. Berkman ND, Sheridan SL, Donahue KE, Halpern DJ, Viera A, Crotty K, et al. Health Literacy Interventions and Outcomes: An Updated Systematic Review 2011: Agency for Healthcare Research and Quality (US).

36. Nouri SS, Rudd RE. Health literacy in the "oral exchange": an important element of patient-provider communication. Patient Educ Couns. 2015;98: 565-71. https://doi.org/10.1016/j.pec.2014.12.002

37. Schaeffer D, Hurrelmann K, Bauer U, Kolpatzik K. National Action Plan on Health Literacy. Strengthen the Health Literacy in Germany [Nationaler Aktionsplan Gesundheitskompetenz. Die Gesundheitskompetenz in Deutschland stärken]. Berlin: KomPart; 2018.

38. Pelikan JM, Dietscher C. Why should and how can hospitals improve their organizational health literacy? [Warum sollten und wie können Krankenhäuser ihre organisationale Gesundheitskompetenz verbessern?] Bundesgesundheitsblatt Gesundheitsforschung Gesundheitsschutz. 2015;58: 989-95. https://doi.org/10.1007/s00103-015-2206-6.

39. Kowalski C, Lee S-YD, Schmidt A, Wesselmann S, Wirtz MA, Pfaff H, Ernstmann $\mathrm{N}$. The health literate health care organization 10 item questionnaire (HLHO-10): development and validation. BMC Health Serv Res. 2015:15:47. https://doi.org/10.1186/s12913-015-0707-5.

40. Brach C, Keller D, Hernandez LM, Baur C, Parker R, Dreyer B, et al. Ten attributes of health literate health care organizations. Washington, DC: Institute of Medicine of the National Academies; 2012. p. 1-27.

41. Dillman DA. Mail and Telephone Surveys: The Total Design Method. New York: Wiley; 1978

42. Halbach SM, Ernstmann N, Kowalski C, Pfaff H, Pförtner T-K, Wesselmann S, Enders A. Unmet information needs and limited health literacy in newly diagnosed breast cancer patients over the course of cancer treatment. Patient Educ Couns. 2016:99:1511-8. https://doi.org/10.1016/j.pec.2016.06.028.

43. Schmidt A, Ernstmann N, Wesselmann S, Pfaff H, Wirtz M, Kowalski C. After initial treatment for primary breast cancer: information needs, health literacy, and the role of health care workers. Support Care Cancer. 2016;24: 563-71. https://doi.org/10.1007/s00520-015-2814-6.

44. Hox JJ. Multilevel analysis: techniques and applications. 2nd ed New York NY u.a.: Routledge; 2010

45. Snijders TAB, Bosker RJ. Multilevel analysis: an introduction to basic and advanced multilevel modeling. 2nd ed Los Angeles Calif. u.a.: SAGE Publ; 2012.

46. Ernstmann N, Halbach S, Kowalski C, Pfaff H, Ansmann L. Measuring attributes of health literate health care organizations from the patients' perspective: development and validation of a questionnaire to assess health literacy-sensitive communication (HL-COM). Z Evid Fortbild Qual Gesundhwes. 2017:121:58-63. https://doi.org/10.1016/j.zefq.2016.12.008.

47. Say R, Murtagh $M$, Thomson R. Patients' preference for involvement in medical decision making: a narrative review. Patient Educ Couns. 2006:60: 102-14. https://doi.org/10.1016/j.pec.2005.02.003.

48. Paasche-Orlow MK, Parker RM, Gazmararian JA, Nielsen-Bohlman LT, Rudd RR. The prevalence of limited health literacy. J Gen Intern Med. 2005;20:17584. https://doi.org/10.1111/j.1525-1497.2005.40245.x.

49. Farmanova E, Bonneville L, Bouchard L. Organizational health literacy: review of theories, frameworks, guides, and implementation issues. Inquiry. 2018:55:46958018757848. https://doi.org/10.1177/0046958018757848.

50. O'Cathain A, Murphy E, Nicholl J. Three techniques for integrating data in mixed methods studies. BMJ. 2010;341:c4587. https:/doi.org/10.1136/bmj.c4587.

51. Axinn WG, Pearce LD. Mixed method data collection strategies. Cambridge: Cambridge University Press; 2006

52. Scholl I, LaRussa A, Hahlweg P, Kobrin S, Elwyn G. Organizational- and system-level characteristics that influence implementation of shared decision-making and strategies to address them - a scoping review. Implement Sci. 2018;13:40. https://doi.org/10.1186/s13012-018-0731-z.

53. Siegrist J, editor. Social inequalities in health: New evidence and policy implications. 1st ed. Oxford: Oxford Univ. Press; 2010.

Ready to submit your research? Choose BMC and benefit from

- fast, convenient online submission

- thorough peer review by experienced researchers in your field

- rapid publication on acceptance

- support for research data, including large and complex data types

- gold Open Access which fosters wider collaboration and increased citations

- maximum visibility for your research: over $100 \mathrm{M}$ website views per year

At $\mathrm{BMC}$, research is always in progress.

Learn more biomedcentral.com/submission 